\title{
Powder bed binder jet printed alloy 625: densification, microstructure and mechanical properties
}

Amir Mostafaei ${ }^{1}$, Erica L. Stevens, Eamonn T. Hughes, Shannon D. Biery, Colleen Hilla, Markus Chmielus* $^{*}$

Department of Mechanical Engineering and Materials Science, University of Pittsburgh, Pittsburgh, PA 15261, USA

* Corresponding author: Markus Chmielus, Email address: chmielus@ pitt.edu, Tel: +1-412-6248176

${ }^{1}$ Amir Mostafaei, Email address: amm397@ pitt.edu

\begin{abstract}
Powder bed binder jet printing is an additive manufacturing method in which powder is deposited layer-by-layer and selectively joined in each layer with binder. Since the powder does not melt during printing, the density after printing is about $50 \%$, and sintering is needed to densify as-printed parts. In this study, we investigate the effect of sintering temperature on density, microstructure, phase formation and mechanical properties of power bed binder jet printed alloy 625 parts. To determine the sintering temperatures, the as-received powder was subjected to differential scanning calorimetry analysis, and printed samples were cured and sintered at various temperatures under high vacuum. Density measurements, elemental analysis, phase formation and microstructure of as-printed, cured and sintered samples were investigated compared with mechanical properties. Results indicate that a fully densified parts with densities of up to $99.6 \%$, as well as favorable mechanical properties (hardness of up to $238 \mathrm{HV}_{0.1}$ and UTS of up to $612 \mathrm{MPa}$ ) may be obtained for the sample sintered at $1280{ }^{\circ} \mathrm{C}$. It is concluded that alloy 625 produced by powder bed binder jet printing can achieve similar density and mechanical properties as cast alloy 625 .
\end{abstract}

Keywords: Additive manufacturing; Inconel 625; Nickel Superalloy; Argon atomized powder; Phase Formation; Sintering.

\section{Introduction}

Additive manufacturing (AM) can be defined as a process of selectively adding material, usually layer upon layer, to create an object from three-dimensional (3D) model data. AM provides the possibility of directly manufacturing parts with complex in- and external designs, with limited material and chemical waste, superior control of part size and shape, and rapid prototype creation from various materials such as metal, polymer, ceramic, sand and glass [1,2]. This is in contrast to subtractive manufacturing, where material is selectively removed to create the desired shape.

In recent years, Ni-based parts have been created by different AM methods, namely selective laser melting (SLM) [3,4], electron beam melting (EBM) [5] or powder bed binder jet printing (BJP) [6]. While SLM and EBM create parts with thermally-induced residual stresses and distortions due to large thermal gradients, BJP takes place at room temperature (RT), thus, does not introduce residual stress or distortions during the printing process but following densification heat treatment. During BJP (1) powder is deposited layer-by-layer, (2) selectively joined with a binder, (3) that subsequently gets cured above RT so that the part is carefully manipulable, (4) 
the part gets sintered and sometimes HIPped [6,7]. New materials and processing are the focus of BJP of metallic parts for Rapid Tooling and subject to current research, as done here.

To enable a wider adoption of BJP by the manufacturing industry, the porosity, microstructural features and mechanical properties of the Ni-based superalloy parts require further improvement. It is well known that the most important microstructural characteristic affecting adaption of superalloys is porosity [6]. This is because pores suffer from high stress concentrations, which promote the initiation and growth of cracks. Therefore, reducing porosity in printed parts made by BJP is of most importance to improve mechanical properties.

The term superalloy denotes an alloy that shows numerous key characteristics, namely excellent mechanical strength, resistance to thermal creep deformation, good surface stability and resistance to high temperature corrosion or oxidation [8-11]. Recently, researchers have successfully printed and characterized the alloy 718 at high relative density using BJP [6]. Another Ni-based superalloy used in engineering applications is alloy 625, which exhibits a good combination of yield strength, creep strength, fatigue strength, excellent oxidation and corrosion resistance in aggressive environments [11,12]. Furthermore, its good machinability and weldability have made it the primary choice for many applications in aerospace, chemical, petrochemical and marine applications. However, many alloy 625 components are highly complex shapes that are very expensive to produce due to extensive machining [13]. AM, especially BJP, can overcome the machining issues and result in even more complex parts.

This work focuses on the effect of sintering temperature on the porosity reduction to improve mechanical properties in BJP alloy 625 parts along with improved microstructure and phases present in the sintered parts. Initially, the as-received feedstock powder was fully characterized to better choose sintering conditions. Porosity distribution and density of the as-printed and consolidated samples were identified. Microstructural observations, compositional analyses and phase formation were studied with regards to different heat treatments and compared to mechanical properties. This approach can be utilized to develop reliable designs for industrial applications of alloy 625 parts. We show that properly sintered BJP parts have mechanical properties (such as ductility, tensile strength (UTS) and hardness) that are similar to cast alloy 625 properties making BJP a viable AM method for Ni-based superalloy part production.

\section{Materials and methods}

In this study, vacuum-melted argon atomized alloy 625 powder from Carpenter Technology Corporation was utilized. The chemical composition (provided by manufacturer and compared to measurements of this study) and size limits of the feedstock powder is given in Table 1. Additionally, the water based binder was provided by ExOne Company with the compositions of ethylene glycol monobutyl ether (10 volume percent, CAS \# 111-76-2) and ethylene glycol (20 volume percent, CAS\# 107-21-1).

In order to predict the sintering behavior of the BJP samples, differential scanning calorimetry (DSC) was conducted on the powder by heating a powder sample up to $1350{ }^{\circ} \mathrm{C}$ at $10{ }^{\circ} \mathrm{C} / \mathrm{min}$ with a TA instrument, Q 600 Series DSC in ultra-high purity $\operatorname{Ar}(100 \mathrm{~mL} / \mathrm{min})$.

The particle size distribution by volume and number was analyzed using a Microtrac S3500 trilaser laser diffraction particle analysis system via algorithms for spherical particles. Three powder particles samples of approximately $1 \mathrm{~g}$ were suspended isopropyl alcohol which also prevented agglomeration. 
Powder morphology and elemental composition analyses were conducted using a JEOL (JSM 6510) scanning electron microscope (SEM) equipped with energy dispersive X-ray spectroscopy (EDS). XRD was performed on a PANanalytical X-ray diffractometer with a Co $\mathrm{K}_{\mathrm{a}}$ radiation source $(\lambda=1.79 \AA)$ operated at $40 \mathrm{kV}$ and $40 \mathrm{~mA}$ in the $2 \theta$ ranging from $35^{\circ}$ to $115^{\circ}$ at $0.02^{\circ} / \mathrm{s}$.

General morphology and internal porosity of the powder particles, as-printed samples and sintered samples were visualized with a Bruker SkyScan1272 micro-computed tomography scanner (microCT) at $100 \mathrm{kV}$ and $100 \mu \mathrm{A}$ and a $0.11 \mathrm{~mm} \mathrm{Cu}$ filter. Powder samples were filled into a low absorbance $1.5 \mathrm{~mm}$ plastic straw, compacted to reduce particle movement and scanned without random movement. The angular range was $0^{\circ}-180^{\circ}$ with steps of $0.2^{\circ}$ and $0.3^{\circ}$. An averaging of 10 frames was used.

An M-Flex ExOne powder bed binder jet printer was used to produce alloy 625 parts with the following printing parameters: layer height of $100 \mu \mathrm{m}$, recoat speed of $130 \mathrm{~mm} / \mathrm{s}$, oscillator speed of $2050 \mathrm{rpm}$, roller speed of $250 \mathrm{rpm}$, roller traverse speed of $15 \mathrm{~mm} / \mathrm{s}$, and drying speed of $17 \mathrm{~mm} / \mathrm{s}$. Figure 1 shows an image of representative tensile sample.

After completing the printing process, the resulting semi-finished products ("green parts") were cured at $175^{\circ} \mathrm{C}$ in a JPW Design \& Manufacturing furnace and then sintered in a Lindberg tube furnace in a alumina powder bed under vacuum with the following heating profile: heating at 5 ${ }^{\circ} \mathrm{C} / \mathrm{min}$ from RT to $600{ }^{\circ} \mathrm{C}, 3.2{ }^{\circ} \mathrm{C} / \mathrm{min}$ to $1000{ }^{\circ} \mathrm{C}, 2.8{ }^{\circ} \mathrm{C} / \mathrm{min}$ to the holding temperature (1200, 1220, 1240, 1260, 1280, 1290 and $1300{ }^{\circ} \mathrm{C}$ ), holding for $4 \mathrm{~h}$ and then cooling at $1{ }^{\circ} \mathrm{C} / \mathrm{min}$ to $1200{ }^{\circ} \mathrm{C}, 3.1^{\circ} \mathrm{C} / \mathrm{min}$ to $500{ }^{\circ} \mathrm{C}$ and finally to RT inside the furnace.

Density and volume changes (shrinkage) of the as-printed and sintered samples were measured via an Archimedes principle setup with an OHAUS AX324 precision balance (0.1 mg accuracy). Density of the sintered samples was also determined from cross sectional optical micrographs of the samples using ImageJ image analyzing software. For microstructural examination of the sintered coupons, cross sections were cut from the specimens, mounted, ground and polished using a Struers (Model Tegramin-25) automatic system according to [14]. After surface preparations, samples were etched with a Kalling solution (ASTM E407, \# 94) and Keyence digital optical microscope (DOM) micrographs were taken (dark field Z20 lens and multidiffused adapter). Microstructural characterizations, compositional analyses and surface fracture investigations were conducted using JEOL (JSM 6510) SEM equipped with EDS. The d-spacing values and lattice parameters were determined at different heat treatments with the same XRD and scan parameters used during as-received powder analysis.

Vickers microhardness tests were performed on the cross section of sample at different heat treatment stages with a Leco LM 800 microhardness tester (load of $100 \mathrm{gf}$, dwell time of $10 \mathrm{~s}$ ). Rate controlled tensile tests at $5 \mathrm{~mm} / \mathrm{min}$ were performed on samples sintered at 1280, 1290 and $1300{ }^{\circ} \mathrm{C}$ using a MTS 880. For the mechanical testing, an ASTM standard test method for tension testing of metallic materials (ASTM Standards, vol. 03.01. Designation E8-04) was used.

\section{Results and discussions \\ 3.1. Powder feedstock}

Morphology - exemplary size distribution, cross section microstructure and the interdendritic precipitates - of the rapid solidified vacuum-melted argon atomized powders are shown in Figure 2. Most powder particles are spherical in shape (Figure 2a) with particle size distribution of 16$53 \mu \mathrm{m}$. The individual powder has a dendritic structure typical of rapid solidification and a large amount of precipitates exist in the interdendritic area (Figure 2b). These precipitates have script 
morphology and exist throughout the entire interdendritic area. We assume that these precipitates are the Laves phase, which is the final solidification product of Ni-based superalloys [15]. Additionally, one EDS scan spectrum and results (relative error of EDS can be as high as 2\%) of the as-received feedstock powder are given in Table 1, respectively, showing agreement within the relative error with the manufacturer-provided values (Table 1). Powder XRD (Figure 2c) showed that the main peaks are related to the prevalent fcc $\gamma$-Ni phase [16]. Since Mo and $\mathrm{Nb}$ were present in the matrix as solid solution hardening alloying elements, no characteristic peaks were detected for these elements. During powder production, some intermetallic phases such as $\gamma^{\prime}\left[\mathrm{Ni}_{3}(\mathrm{Al}, \mathrm{Ti})\right], \gamma^{\prime \prime}\left[\mathrm{Ni}_{3}(\mathrm{Nb}),\right]$ and $\delta\left[\mathrm{Ni}_{3} \mathrm{Nb}\right]$ may be precipitated in the $\gamma$-Ni matrix. The amount of these intermetallic phases is usually very low and was not be detected by XRD due to their very fine nature. However, the calculated lattice parameter of the $\gamma$-Ni matrix indirectly indicate the nature of precipitation [13]. The reference lattice parameter and three main peaks of the fcc $\gamma$ Ni phase (Reference code: 98-011-6293) were compared to the peak positions, d-spacing and lattice parameters of the alloy 625 powder (Table 2). The used alloy 625 powders showed an increased lattice parameter of about $0.52 \%$ most likely due to the presence of various alloying elements dissolved in the matrix. The peak shifts to the left were probably precipitate formation on the outer surface and inside the powders during the atomization process. The over three measurement cycles averaged nominal Microtrac powder size distribution data by volume and count is given in Figure 2 d. The feedstock powder had a size distribution from 14 to $65 \mu \mathrm{m}$, which is a slightly larger than the manufacturer provided values. The particle size distribution values were: $\mathrm{d}_{10}=21 \mu \mathrm{m}, \mathrm{d}_{50}=31.8 \mu \mathrm{m}$ and $\mathrm{d}_{90}=45.1 \mu \mathrm{m}$ (see Figure $2 \mathrm{~d}$ ).

MicroCT scans of the as-received powder revealed the already-observed powder particle morphology and additionally porosity within powder particles (Figure 3).

To determine the appropriate sintering temperature range for our samples, the powder DSC measurements (Figure 4) were analyzed showing that melting begins at $1304{ }^{\circ} \mathrm{C}$ and ends at $1334{ }^{\circ} \mathrm{C}$, which is in the range of reported values of cast alloy 625 materials between 1290 and $1350{ }^{\circ} \mathrm{C}$ [11] and close to the solidus of $1294{ }^{\circ} \mathrm{C}$ for an alloy 625 powder reported by Simchi [17]. The difference between the reported and measured solidus temperatures is due to the difference in chemical composition and median particle size. Furthermore, lower specific surface energy of bulk samples results in higher solidus and liquidus temperatures of cast material, which agrees with our findings. Additionally, an oxide layer formation on the surface of the powders can affect the melting temperature [12,18]. Based on the data obtained from DSC analysis, the sintering temperature range was selected to be $1200-1300{ }^{\circ} \mathrm{C}$. The lower sintering temperatures were chosen to observe and prevent surface deformation due to melting.

\subsection{Porosity, microstructure observations and elemental analyses}

Generally, the shape, size and distribution of pores are very important factors in terms of mechanical properties in parts produced by powder metallurgy $[15,19]$. Pores inside the material lead to local stress concentrations, a reduction in the load-carrying area and, consequently, crack initiation and propagation [10]. Small, spherical pores located far from the surface are less detrimental to performance [12].

Optical microscopy (OM) micrographs showing shape, size, and distribution of porosity of the differently sintered samples after polishing are given in Figure 5. The micrographs indicate that sintering at 1200 and $1220{ }^{\circ} \mathrm{C}$ resulted in highly porous samples with interconnected pores. Increasing the sintering temperature led to decreased porosity (fewer, smaller pores). More importantly, the remaining pores were spherical and not interconnected [12]. In general, a 
progression with increasing sintering temperature from irregular, interconnected pores to spherical pores within the grains or located at the grain boundaries was observed (Figure 5). This is a desirable change since spherical pores reduce stress concentrations thereby improving fatigue life and UTS [20-22].

Pore coarsening and its effect on density during final-stage sintering is a well-established phenomenon. Differences in the pore size and curvature leads to growth of the large pores at the expense of the smaller, stable pores [23]. In agreement with the literature, this study found that very high sintering temperatures $\left(1290\right.$ and $\left.1300{ }^{\circ} \mathrm{C}\right)$ resulted in pore coarsening and consequently lower density. The average pore diameter at $1280{ }^{\circ} \mathrm{C}$ was less than $4 \mu \mathrm{m}$, while $1300{ }^{\circ} \mathrm{C}$ resulted in pore coarsening to a diameter of $10 \mu \mathrm{m}$.

Grain morphology affects properties such UTS, fatigue life, corrosion and high temperature oxidation as known from powder metallurgy. The micrographs of etched cross sections of samples sintered at 1280,1290 and $1300{ }^{\circ} \mathrm{C}$ are clearly showing grain growth with increasing sintering temperature (Figure 6). Pores were mostly inside the grains at 1280 and $1290{ }^{\circ} \mathrm{C}$ while between grains at $1300{ }^{\circ} \mathrm{C}$. In all three samples, equiaxial grains were observed. The average grain size (analyzed with ImageJ on SEM micrographs) increased with sintering temperature from $55 \pm 15 \mu \mathrm{m}\left(1280{ }^{\circ} \mathrm{C}\right)$ to $103 \pm 32 \mu \mathrm{m}\left(1290{ }^{\circ} \mathrm{C}\right)$ and $182 \pm 31 \mu \mathrm{m}\left(1300{ }^{\circ} \mathrm{C}\right)$. Additionally, the average grain diameter for each samples was compared with the ASTM E-112-13 and found the grain size number as follows: 5-6 levels $\left(1280{ }^{\circ} \mathrm{C}\right)$, 3-4 levels $\left(1290^{\circ} \mathrm{C}\right)$ and $1.5-2.5$ levels $(1300$ ${ }^{\circ} \mathrm{C}$ ). Ozgun et al. [12] reported that samples prepared by powder injection molding (PIM) sintered at $1290{ }^{\circ} \mathrm{C}$ provided the highest density and showed equiaxial grains with an average grain size of 100-150 $\mu \mathrm{m}$. Turker et al. [6] used powder between 20 and $53 \mu \mathrm{m}$ and reported that the grain size of the alloy 718 printed by BJP and sintered at $1280{ }^{\circ} \mathrm{C}$ was $100-150 \mu \mathrm{m}$, which is larger and less favorable than grain sizes produced in the present study.

\subsection{Density measurements}

Density measurements were conducted on both as-printed and sintered alloy 625 samples. Figure 7 shows a microCT cross sectional image of a green (as-printed) part with a density of about $60 \%$. Lower density parallel lines indicate an irregular powder distribution potentially caused by the oscillator that is meant to densify the green sample. Immersion testing of the green sample showed a 53\% overall density which is in good agreement with the microCT results.

Relative density results (Archimedes and from $\mathrm{OM}$ on cross sections) for all sintering temperatures are summarized in Figure $8 \mathrm{a}$ showing density increases with increasing temperature. Sintering at $1200{ }^{\circ} \mathrm{C}$ and $1220{ }^{\circ} \mathrm{C}$ resulted in porous samples with densities of approximately $79 \%$. By increasing the sintering temperature, the highest relative density of $99.6 \%$ was reached at $1280{ }^{\circ} \mathrm{C}$, which is less than the solidus temperature of the alloy 625 powders (as determined by DSC). Samples sintered at 1290 and $1300{ }^{\circ} \mathrm{C}$ had densities lower than $99 \%$ when measured via immersion and steady in OM observations. This disparity is most likely due to alumina particles with lower density attached to the surface of the sample that were not able to be removed before immersion testing. It is worth noting that part distortion and shape changes were seen at $1290{ }^{\circ} \mathrm{C}$ and above, indicating an excess of the liquid phase. Shrinkage of the BJP samples after sintering at different times is given in Figure $8 \mathrm{~b}$ and was about $5 \%$ dimension change ( $14 \%$ volume reduction) for the sample sintered at $1200{ }^{\circ} \mathrm{C}$. Increasing the sintering temperature resulted to more shrinkage as seen in Figure $8 \mathrm{~b}$ with the maximum shrinkage of about $18.7 \%$ (about $46.3 \%$ volume change) for the samples sintered at $1280{ }^{\circ} \mathrm{C}$ and higher temperatures with densities $>99 \%$. Turker et al. [6] studied the shrinkage behavior of 
alloy 718 nickel-based super alloy fabricated by BJP and found that it was about $20 \%$ at the optimum sintering temperature resulting in the highest density value.

As mentioned above, smaller powder particles provide higher surface energy, which results in higher density values sooner at constant sintering temperatures [23]. It is reported that a relative density of $96 \%$ with an average particle size of $12.5 \mu \mathrm{m}$ as a result of sintering performed for $2 \mathrm{~h}$ in $5 \%$ hydrogen and argon at $1235^{\circ} \mathrm{C}$ [26]. A difference in the obtained results in this study is due to the larger particle size used, since the driving force of sintering is a decrease in surface energy [18,25]. Ozgun et al. reported that powder injection molded alloy 625 powders with the average particle size of $11.1 \mu \mathrm{m}$ sintered at $1300{ }^{\circ} \mathrm{C}$ for $3 \mathrm{~h}$ resulted in $98 \%$ density. In other words, smaller sized powder particles provide higher surface energy, therefore, it is possible to obtain higher density values with shorter sintering times [12]. The higher density obtained here may be attributed to better density in the green state and optimized sintering temperature and time in the high vacuum condition.

SEM micrographs for microstructural and morphological are illustrated in Figure 9 and show similarly to OM micrographs small amounts of porosity in intergranular regions. Additional, compositional EDS analyses show segregation and phase formation inter- and intra-granular. At $1200{ }^{\circ} \mathrm{C}$ (Figure 9a), the sintering temperature was not high enough to eliminate porosity between the sintered powder particles and achieve fully densified samples. Higher-magnification observations revealed the formation of small, light-colored precipitates inside the grains and in the grain boundaries with enriched in $\mathrm{Nb}$ and $\mathrm{C}$ (EDS), suggesting the formation of $\mathrm{NbC}$ carbide [27,28]. Increasing the sintering temperature to $1240{ }^{\circ} \mathrm{C}$ resulted in a reduction in the porosity with closed and disconnected pores (Figure 9b) confirming OM and density measurement findings. The number and size of light-colored precipitates in the grain boundaries increased with increasing sintering temperature and EDS results suggesting the formation of MC type NbC [12]. Carbon and oxygen contents (wt.-\%) were measured in the as-received powders as well as the printed and cured samples and increased from 0.04 and 0.02 wt.- $\%$ to 0.47 and 0.23 wt.- $\%$, for carbon and oxygen, respectively. Therefore, the formation of precipitates inside the grains and at the grain boundaries might be related to the presence of the residual $\mathrm{C}$ and $\mathrm{O}$ which react with alloying elements such as $\mathrm{Cr}, \mathrm{Nb}$ and $\mathrm{Mo}$ at high temperatures.

Micrographs of samples sintered at $1280{ }^{\circ} \mathrm{C}$ show bright light structures at the grain boundaries with increased $\mathrm{Nb}, \mathrm{Cr}$ and Mo content probably liquid phase formed during sintering (Figure 9c and Table 3) with the following observations: (1) at point 2 the composition was very close to that of alloy 625 representing the matrix. (2) point 1 (the grain boundary) had higher oxygen than any other point. (3) An increase in $\mathrm{C}$ and $\mathrm{Nb}$ at point 1 suggests that $\mathrm{MC}$ type $\mathrm{NbC}$ has formed. (4) At point 4, $\mathrm{Ni}$ and $\mathrm{Nb}$ were the dominant elements, suggesting $\delta$ phase $\left(\mathrm{Ni}_{3} \mathrm{Nb}\right)$. (5) At point 3 , where the grain boundary carbide precipitates are located, the compositional formula is suggested to be $\mathrm{M}_{6} \mathrm{C}$. This phase tends to be formed in alloys rich in refractory metals such as Mo and $\mathrm{W}[12,33]$. It is reported that $\mathrm{M}_{6} \mathrm{C}$-type carbides form as grain boundary precipitates in alloys containing more than 6-8\% Mo or W [18]; in the current study, powder with 8.9 wt.-\% Mo is used. Carbide precipitates can be formed in Ni-based superalloys during solidification [34]; therefore, the observed MC carbides likely formed during the cooling stage of the sintering process.

EDS elemental analyses conducted on samples sintered at 1290 and $1300{ }^{\circ} \mathrm{C}$ (Figure 9d-e) revealed that the bright spots in the grain boundaries (points 5 and 7) were $\mathrm{Nb}$ - and $\mathrm{C}$-rich, suggesting a $\mathrm{NbC}$ carbide formation with a higher amount in the sample sintered at $1300{ }^{\circ} \mathrm{C}$ 
(Figure 9e). Points 6 and 8 indicated areas close to the alloy 625 standard composition, representing the matrix. The SEM micrographs of the sample sintered at $1300{ }^{\circ} \mathrm{C}$ (Figure 9e) illustrate that an increased sintering temperature not only caused the formation of liquid phase in the grain boundaries (enriched in $\mathrm{Nb}, \mathrm{Cr}$ and $\mathrm{Mo}$ ), but also resulted in less uniformity of these elements: decreased within grains and increased at grain boundaries.

The refractory elements $\mathrm{Nb}$, Mo and $\mathrm{Mn}$ added to the Ni-based superalloy improve the strength of these alloys by forming solid solution and/or formation of topologically close packed phase (TCP). Thus, small changes in the distribution of refractory elements affect the precipitation kinetics and stability of the different intermetallic phases in the matrix [12-14]. Refractory elements Mo and Cr cause active solid solution hardening in Ni-based superalloys, and have higher moduli and melting temperatures than $\mathrm{Nb}$. Alloy 625 was initially designed to gain strength through solid solution hardening; however, it is known that higher strength may be obtained by aging which produces $\mathrm{Ni}_{3} \mathrm{Nb}$ precipitation [12,24]. Therefore, it is important that $\mathrm{Nb}$ is present without carbide formation which is more difficult in BJP samples due to the residual C from the binder.

\subsection{Phase formation study by XRD}

XRD patterns of the sintered samples had additional (compared to feedstock powder) small peaks indicating the formation of precipitates of intermetallic phases such as $\gamma^{\prime}\left(\mathrm{Ni}_{3} \mathrm{Al}\right), \gamma^{\prime}$ $\left(\mathrm{Ni}_{3} \mathrm{Nb}\right), \delta\left(\mathrm{Ni}_{3} \mathrm{Nb}\right)$ and various carbides during the sintering process (Figure 10). However, these intermetallic phases were not easily detected by XRD due to their small diffraction volume. Even so, the lattice parameter of the $\gamma$-matrix diffraction peaks can indirectly indicate the nature of precipitation. The lattice parameter of the $\gamma$-Ni matrix of the as-received powder was determined by XRD to be $3.5996 \AA$.

In this study, sintered samples were allowed to cool down slowly within the furnace which leads to the formation of $\delta$ phase precipitates [12]. The $\delta$ phase was detected in all sintered samples' XRD patterns. Sintered above $1260{ }^{\circ} \mathrm{C}$, NbC peaks were detected, indicating that the carbide has enough time to form while above the solidus temperature, and during cooling.

Although the sintering process was conducted under high vacuum, chromium oxide $\left(\mathrm{Cr}_{2} \mathrm{O}_{3}\right)$ precipitate were identified with increasing amounts at increasing temperatures of up to $1280{ }^{\circ} \mathrm{C}$ (higher XRD peak volume), formed most likely due to a high oxidation speed at high temperatures of alloy $625[12,24,32]$. However, the amount of $\mathrm{Cr}_{2} \mathrm{O}_{3}$ decreased from $1280{ }^{\circ} \mathrm{C}$ to $1300{ }^{\circ} \mathrm{C}$. This may be due to the evaporation of some of the $\mathrm{Cr}_{2} \mathrm{O}_{3}$ above $1280{ }^{\circ} \mathrm{C}$. The evaporation of $\mathrm{Cr}_{2} \mathrm{O}_{3}$ as $\mathrm{CrO}_{3}$ gas at temperatures above $1000{ }^{\circ} \mathrm{C}$ is reported in [12]. $\mathrm{Thus}, \mathrm{Cr}_{2} \mathrm{O}_{3}$ decomposes into $\mathrm{Cr}$ and $\mathrm{CrO}_{3}$, then $\mathrm{CrO}_{3}$ evaporates and the $\mathrm{Cr}$ that is left behind from the oxide decomposition dissolves into the matrix [33]. In Ni-based superalloys, different types of oxide phases may occur. The most protective of these are aluminum oxide $\left(\mathrm{Al}_{2} \mathrm{O}_{3}\right)$ and chromium oxide $\left(\mathrm{Cr}_{2} \mathrm{O}_{3}\right)$ which need oxygen and a sufficient amount of $\mathrm{Cr}$ and $\mathrm{Al}$ content to grow and temperatures above $1260{ }^{\circ} \mathrm{C}$. In fact, the role of $\mathrm{Cr}$ is to ensure formation of a thin, green $\mathrm{Cr}_{2} \mathrm{O}_{3}$ on the outer surfaces. In general, $\mathrm{Cr}_{2} \mathrm{O}_{3}$ can form inside or on the surface of alloy 625 , depending on the amount of Cr. Pyczak et al. [34] reported that in the Ni-based alloys with 10-30 vol.-\% $\mathrm{Cr}, \mathrm{Cr}_{2} \mathrm{O}_{3}$ was observed as external scales above the grain boundaries in addition to internal $\mathrm{Cr}_{2} \mathrm{O}_{3}$, which are both expected to form in our sintered parts with $21.2 \mathrm{wt}$ - $\%$ of $\mathrm{Cr}$ [34].

The XRD peak analysis of d-spacing and lattice parameter, leads to a better understanding of the precipitation/dissolution of various intermetallics and carbides in the alloy 625 without 
extracting the precipitates from the matrix. Figure $10 \mathrm{~b}$ illustrates the $2 \theta$ decrease (d-spacing increase) of the Ni- $\gamma$ (111) XRD peak with increasing sintering temperature. We assume that by increasing the sintering temperature, $\mathrm{Nb}$, $\mathrm{Mo}$ and $\mathrm{Cr}$, which participate in the formation of carbides and precipitates, can dissolve in the nickel matrix, resulting in increasing d-spacing values. A summary of the XRD results are given in Table 4. Figure $10 \mathrm{~b}$ details the overlapping $\gamma$ $\mathrm{Ni}$ matrix and $\mathrm{NbC}$ peaks (left) and $\delta$ phase peak (right). By increasing the sintering temperature, the intensity of the right peak increases, which can be attributed to the formation of $\mathrm{NbC}$ and $\delta$ phases found in the grain boundaries [12,13]. Although these phases are expected to remain mostly in the grain boundaries with increasing sintering temperatures, they may partially dissolve in the matrix, resulting in the reduction in peak density.

\subsection{Mechanical properties}

\subsubsection{Microhardness}

Microhardness measurements results are summarized in Figure 11a showing a hardness increase from $107.2 \pm 24.7 \mathrm{HV}_{0.1}$ to $237.4 \pm 4.9 \mathrm{HV}_{0.1}$ with increasing sintering temperature (1200 to $1280{ }^{\circ} \mathrm{C}$ ) and then decreased to $185.4 \pm 4.2 \mathrm{HV}_{0.1}$ for the $1300{ }^{\circ} \mathrm{C}$ sample. Just considering density, which increases with increasing sintering temperature, the hardness of the samples should increase. However, with increasing sintering temperature and time, grain growth or coarsening as well as segregation of alloying elements to the grain boundary has an opposite effect on the hardness $[11,23,28,34]$. Thus, varying contributions to the hardness are dominant at different sintering conditions and are visible in the density measurements, OM and SEM/EDS observations. Similar results were reported by Ozgun et al. for traditionally-manufactured Nibased superalloys [12,18,24,25].

\subsubsection{Tensile tests}

Tensile test curves of fully densified alloy 625 samples $\left(1280{ }^{\circ} \mathrm{C}\right.$ to $\left.1300{ }^{\circ} \mathrm{C}\right)$ are summarized in Figure $11 \mathrm{~b}$ with the $1280{ }^{\circ} \mathrm{C}$ sample showing the highest UTS of $612 \mathrm{MPa}$ with a $41 \%$ elongation. However, by increasing the sintering temperature to $1290{ }^{\circ} \mathrm{C}$ and $1300{ }^{\circ} \mathrm{C}$, the UTS decreased to 588 and $522 \mathrm{MPa}$, respectively. The yield stress of the $1280{ }^{\circ} \mathrm{C}$ sample was 327 $\mathrm{MPa}$ with increasing sintering temperature decreasing the yield stress values. We propose that with increasing sintering temperature from 1280 to $1300{ }^{\circ} \mathrm{C}$, (1) grain coarsening occurs, (2) alloying elements segregate in the grain boundaries, (3) Laves phase forms at the grain boundaries enriched with $\mathrm{Nb}$ and $\mathrm{Mo}$, (4) $\mathrm{NbC}$ form in the matrix, all resulting in decreasing UTS and yield stress, similarly to the microhardness and supported by microstructural observations. The fracture strain increased to $45.0 \%$ for the $1290{ }^{\circ} \mathrm{C}$ and then declined to $35.6 \%$ for the $1300{ }^{\circ} \mathrm{C}$ sample. Since carbides are dissolved in the microstructure of the samples sintered at $1290{ }^{\circ} \mathrm{C}$, the possibility of initiation and propagation of microcracks decreases in the grain boundaries which may lead to the increase of elongation.

Comparing the results of the $1280{ }^{\circ} \mathrm{C}$ sample with reported values of Ozgun et al. for PIM prepared alloy 625 samples sintered at $1300{ }^{\circ} \mathrm{C}$ for $3 \mathrm{~h}$ with a UTS of $650 \mathrm{MPa}$ and $45 \%$ elongation and cast alloy 625 [11] had a UTS of $710 \mathrm{MPa}$ with $48 \%$ elongation shows that BJP samples with optimal sintering conditions reach similar mechanical properties as conventional casting or powder metallurgy techniques. Small differences are attributed to particle size and sample preparation differences. 


\subsubsection{Fractography}

Figure 12 illustrates an exemplary SEM fractograph of the $1280{ }^{\circ} \mathrm{C}$ sample indicating ductile failure detailed by ductile dimple fracture. EDS analysis on the fracture surface are given in Table 5. Point 1 has the same chemical composition as the initial powders, while point 2 shows precipitates in the microstructure. In Ni-based superalloys, some types of topologically closed packed phases are important - such as $\sigma$ and $\mu$ phases. Generally, the $\sigma$ phase consists of atoms with approximately equal sizes such as $\mathrm{Ni}, \mathrm{Cr}$ and $\mathrm{Fe}$, while the $\mu$ phase consists of elements with different atom sizes such as $\mathrm{W}$ and $\mathrm{Co}$ [12]. The region at point 2 was enriched in $\mathrm{Ni}, \mathrm{Cr}$, $\mathrm{Nb}$, Mo, and $\mathrm{C}$. Thus, it can be suggested that $\mathrm{MC}(\mathrm{NbC})$ and $\sigma$ (FeCrMo, $\mathrm{CrFeMoNi}, \mathrm{CrNiMo})$ phases are present [12]. Therefore, it was thought that carbides and TCP phases led to the formation of cracks and failure.

\section{Conclusions}

In this study, additively manufactured samples were successfully printed by the powder bed binder jet printing using alloy 625 powder. The effect of the sintering temperature on density, microstructure, porosity, phase formation, microhardness, UTS and yield stress was investigated. The following conclusions were drawn:

1. The combination of the BJP and optimal sintering conditions results in uniform and fully dense alloy 625 parts. Proper sintering temperature can be determined from DSC powder analysis; here, the solidus and liquidus temperatures were at $1304{ }^{\circ} \mathrm{C}$ and $1334{ }^{\circ} \mathrm{C}$, respectively with an optimum sintering temperature of $1280{ }^{\circ} \mathrm{C}$ and time of $4 \mathrm{~h}$ with the highest UTS of $612 \mathrm{MPa}$, yield strength of $327 \mathrm{MPa}$ and fracture strain of $40.9 \%$. This is comparable to traditionally casted alloy 625 parts

2. Higher than optimum sintering temperatures resulted in grain growth and pore coarsening. OM observations show that the grain diameter of the sample sintered at 1280 ${ }^{\circ} \mathrm{C}$ was between $55 \pm 15 \mu \mathrm{m}$, which is of the order of the powder particle size, and at $1300{ }^{\circ} \mathrm{C}$ of $182 \pm 31 \mu \mathrm{m}$.

3. SEM and XRD studies indicate that by increasing the sintering temperature, different phases appear in the microstructure (both in grain boundaries and inside grains), including $\mathrm{MC}, \mathrm{M}_{6} \mathrm{C}, \delta$, and $\gamma^{\prime \prime}$ precipitates. XRD patterns show that lattice parameter and d-spacing increase with increasing sintering temperature. XRD analysis and SEM examination showed occurrences of mostly $\mathrm{Nb}$ carbides as well as $\mathrm{Cr}_{2} \mathrm{O}_{3}$ in the grain boundaries and inside the grains.

4. Hardness values of increased with increasing sintering temperature, up to a maximum of $237 \mathrm{HV}_{0.1}$ at $1280{ }^{\circ} \mathrm{C}$, being largely a function of density. Increasing the sintering temperature to $1300{ }^{\circ} \mathrm{C}$ led to a reduction in microhardness due to solid solution if alloying elements in the matrix, migrated from the $\gamma-\mathrm{Ni}$ matrix to the grain boundaries.

\section{Acknowledgements}

This project was partially funded by Air Force Research Laboratory under agreement number FA8650-12-2-7230 and by the Commonwealth of Pennsylvania, acting through the Department of Community and Economic Development, under Contract Number C000053981. Partial funding for CH was provided by the NSF CMMI 1434077. ETH and SDB would like to thank the Swanson School of Engineering and the Office of the Provost of the University of Pittsburgh for their partial funding. The authors would like to thank Paul Prichard from Kennametal Inc. for oxygen and carbon analysis of as-printed samples. 


\section{References}

[1] Murr LE, Martinez E, Amato KN, Gaytan SM, Hernandez J, Ramirez D a., et al. Fabrication of Metal and Alloy Components by Additive Manufacturing: Examples of 3D Materials Science. J Mater Res Technol 2012;1:42-54.

[2] Frazier WE. Metal Additive Manufacturing: A Review. J Mater Eng Perform 2014;23:1917-28.

[3] Amato KN, Gaytan SM, Murr LE, Martinez E, Shindo PW, Hernandez J, et al. Microstructures and mechanical behavior of Inconel 718 fabricated by selective laser melting. Acta Mater 2012;60:2229-39.

[4] Ganesh P, Kaul R, Paul CP, Tiwari P, Rai SK, Prasad RC, et al. Fatigue and fracture toughness characteristics of laser rapid manufactured Inconel 625 structures. Mater Sci Eng A 2010;527:7490-7.

[5] Strondl A, Fischer R, Frommeyer G, Schneider A. Investigations of MX and $\gamma^{\prime} / \gamma^{\prime \prime}$ precipitates in the nickel-based superalloy 718 produced by electron beam melting 2008;480:138-47.

[6] Turker M, Godlinski D, Petzoldt F. Effect of production parameters on the properties of IN 718 superalloy by three-dimensional printing. Mater Charact 2008;59:1728-35.

[7] Kim Y. DENSIFICATION AND PROPERTIES EVOLUTION OF STAINLESS STEEL ALLOYS Fabricated by three-dimensional printing. Washingt STATE Univ 2009; Thesis.

[8] Behnamian Y, Mostafaei A, Kohandehghan A, Amirkhiz BS, Serate D, Sun Y, et al. A comparative study on corrosion behavior of stainless steel and nickel-based superalloys in ultra-high temperature supercritical water at 800 C. Corros Sci 2016;106:188-207.

[9] Garcia-Fresnillo L, Chyrkin A, Bo C, Barnikel J, Schmitz F, Quadakkers WJ. Oxidation behaviour and microstructural stability of alloy 625 during long-term exposure in steam. J Mater Sci 2014.

[10] Pollock TM, Rene N. Nickel-Based Superalloys for Advanced Turbine Engines: Chemistry, Microstructure, and Properties. J Propuls Power 2006;22:361-74.

[11] Roger C. Reed. The Superalloys, Fundumentals and Applications. Cambrige University Press; 2006.

[12] Özgün Ö, Özkan Gülsoy H, Yilmaz R, Findik F. Injection molding of nickel based 625 superalloy: Sintering, heat treatment, microstructure and mechanical properties. J Alloys Compd 2013;546:192-207.

[13] Dinda GP, Dasgupta AK, Mazumder J. Laser aided direct metal deposition of Inconel 625 superalloy: Microstructural evolution and thermal stability. Mater Sci Eng A 2009;509:98-104.

[14] ASM-Standard. Metallography and Microstructures of Nonferrous Alloys. ASM Handb 2004;9:711-51.

[15] Chang L, Sun W, Cui Y, Yang R. Influences of hot-isostatic-pressing temperature on microstructure, tensile properties and tensile fracture mode of Inconel 718 powder compact. Mater Sci Eng A 2014;599:186-95.

[16] Azarmi F, Saaedi J, Coyle TW, Mostaghimi J. Microstructure characterization of alloy 625 deposited on nickel foam using air plasma spraying. Adv Eng Mater 2008;10:459-65.

[17] Simchi a. Densification and microstructural evolution during co-sintering of Ni-base superalloy powders. Metall Mater Trans A Phys Metall Mater Sci 2006;37:2549-57.

[18] Özgün Ö, Gülsoy HÖ, Yilmaz R, Findik F. Microstructural and mechanical 
characterization of injection molded 718 superalloy powders.pdf. J Alloys Compd 2013;576:140-53.

[19] Mueller J, Shea K, Daraio C. Mechanical properties of parts fabricated with inkjet 3D printing through efficient experimental design. Mater Des 2015;86:902-12.

[20] Tański T, Brytan Z, Labisz K. Fatigue Behaviour of Sintered Duplex Stainless Steel. Procedia Eng 2014;74:421-8.

[21] Mohamed A. Intergranular Corrosion Fatigue Fracture Surface Analysis of Nickel Alloy. Procedia Eng 2015;114:754-9.

[22] Straffelini G, Benedetti M, Fontanari V. Damage evolution in sinter-hardening powdermetallurgy steels during tensile and fatigue loading. Mater Des 2014;61:101-8.

[23] Dourandish M, Godlinski D, Simchi A, Firouzdor V. Sintering of biocompatible P/M CoCr-Mo alloy (F-75) for fabrication of porosity-graded composite structures. Mater Sci Eng A 2008;472:338-46.

[24] Özgün Ö, Yılmaz R, Özkan Gülsoy H, Fındık F. The effect of aging treatment on the fracture toughness and impact strength of injection molded Ni-625 superalloy parts. Mater Charact 2015;108:8-15.

[25] Özgün Ö, Gülsoy HÖ, Findik F, Yilmaz R. Microstructure and mechanical properties of injection moulded Nimonic-90 superalloy parts. Powder Metall 2012;55:405-14.

[26] Julien B. Metal Injection Moulding: A Near Net Shape Fabrication Method for the Manufacture of Turbine Engine Component 2006.

[27] Wang JW, Wei QS, Liu GC, He YK, Shi YS. Study on Direct Hot Isostatic Pressing Technology for Superalloy Inconel 625. Adv Mater Res 2011;189-193:2935-8.

[28] Sateesh N. Microstructure and mechanical characterization of laser sintered inconel-625 superalloy. Procedia Mater Sci 2014;5:772-9.

[29] Floreen S, Fuchs GE, Yang WJ. The Metallurgy of Alloy 625. Superalloys 718, 625, 706 Var Deriv 1994:13-37.

[30] Kulawik K, Buffat P a., Kruk A, Wusatowska-Sarnek AM, Czyrska-Filemonowicz A. Imaging and characterization of $\gamma^{\prime}$ and $\gamma^{\prime \prime}$ nanoparticles in Inconel 718 by EDX elemental mapping and FIB-SEM tomography. Mater Charact 2015;100:74-80.

[31] List F a., Dehoff RR, Lowe LE, Sames WJ. Properties of Inconel 625 mesh structures grown by electron beam additive manufacturing. Mater Sci Eng A 2014;615:191-7.

[32] Rai SK, Kumar A, Shankar V, Jayakumar T, Bhanu Sankara Rao K, Raj B. Characterization of microstructures in Inconel 625 using X-ray diffraction peak broadening and lattice parameter measurements. Scr Mater 2004;51:59-63.

[33] Rolland R, Issartel C, Perrier S, Buscail H. Effects of 7.5 vol.-\% water vapour on oxidation of nickel based alloy between 900 and $1100^{\circ} \mathrm{C}$. Corros Eng Sci Technol 2011;46:634-41.

[34] Pyczak F, Devrient B, Mughrabi H. The Effects of Different Alloying Elements on the Thermal Expansion Coefficients, Lattice Constants and Misfit of Nickel-Based Superalloys Investigated By X-Ray Diffraction. Superalloys 2004 2004:827-36. 


\section{Table captions}

Table 1: Chemical composition as characterized using EDS.

\begin{tabular}{|l|c|c|c|c|c|c|c|c|c|c|c|c|}
\hline \multicolumn{10}{|c|}{ Composition in weight percent [wt.\%] } \\
\hline Elements & $\mathrm{Ni}$ & $\mathrm{Cr}$ & $\mathrm{Fe}$ & $\mathrm{Nb}$ & $\mathrm{Mo}$ & $\mathrm{Al}$ & $\mathrm{Ti}$ & $\mathrm{C}$ & $\mathrm{Co}$ & $\mathrm{Mn}$ & $\mathrm{Si}$ & $\mathrm{P}$ \\
\hline EDS powder analysis & $\mathrm{Bal}$. & 21.01 & 2.67 & 3.99 & 8.46 & 0.04 & 0.2 & 0.14 & 0.21 & 0.2 & 0.13 & 0.02 \\
\hline Manufacturer analysis & $\mathrm{Bal}$. & 21.20 & 3.09 & 3.63 & 8.91 & 0.05 & 0.01 & 0.03 & $<0.01$ & $<0.01$ & $<0.01$ & $<0.004$ \\
\hline Standard alloy 625 & $>58$ & $20-23$ & $<5.0$ & $3.15-4.15$ & $8-10$ & $<0.4$ & $<0.4$ & $<0.1$ & $<1.0$ & $<0.5$ & $<0.5$ & $<0.015$ \\
\hline
\end{tabular}

Table 2. Crystallographic parameters of the alloy 625 powders compared to the $\gamma$-Ni reference (Reference code: 98-011-6293).

\begin{tabular}{|l|c|c|c|c|}
\hline \multirow{2}{*}{$\begin{array}{l}\text { Crystallographic } \\
\text { planes }\end{array}$} & \multicolumn{2}{|c|}{$\gamma$-Ni (Ref.) } & \multicolumn{2}{c|}{ Alloy 625 powder } \\
\cline { 2 - 5 } & $2 \theta\left[{ }^{\circ}\right]$ & $d[\AA]$ & $2 \theta\left[{ }^{\circ}\right]$ & $d[\AA]$ \\
\hline$(111)$ & 51.272 & 2.0675 & 51.027 & 2.0782 \\
\hline$(200)$ & 59.945 & 1.7905 & 59.582 & 1.8017 \\
\hline$(220)$ & 89.905 & 1.2661 & 89.547 & 1.2710 \\
\hline$(311)$ & - & - & 111.169 & 1.0851 \\
\hline Lattice parameter & $3.581 \AA$ & \multicolumn{3}{|c}{$3.5996 \AA$} \\
\hline
\end{tabular}

Table 3. EDS chemical composition in wt.-\% of the selected points on the SEM image of the sintered sample at $1280{ }^{\circ} \mathrm{C}, 1290{ }^{\circ} \mathrm{C}$ and $1300{ }^{\circ} \mathrm{C}$ (Figure 9).

\begin{tabular}{|l|l|l|l|l|l|l|l|l|}
\hline & $\mathrm{C}$ & $\mathrm{O}$ & $\mathrm{Cr}$ & $\mathrm{Mn}$ & $\mathrm{Fe}$ & $\mathrm{Ni}$ & $\mathrm{Nb}$ & $\mathrm{Mo}$ \\
\hline Point 1 & 53.00 & 1.50 & 0.66 & 0.01 & 0.26 & 1.49 & 41.66 & 1.43 \\
Point 2 & 1.43 & 0.24 & 19.83 & 0.43 & 3.29 & 63.71 & 3.08 & 7.99 \\
Point 3 & 46.04 & 0.45 & 12.19 & 0.02 & 0.53 & 9.58 & 3.02 & 28.17 \\
Point 4 & 2.48 & 0.34 & 1.07 & 0.13 & 0.86 & 68.14 & 24.79 & 2.19 \\
Point 5 & 25.06 & 0.12 & 0.29 & 0.01 & 0.08 & 1.14 & 70.45 & 2.85 \\
Point 6 & 4.59 & 1.20 & 20.39 & 0.22 & 2.97 & 58.93 & 2.92 & 8.79 \\
Point 7 & 23.33 & 0.18 & 0.51 & 0.02 & 0.07 & 1.06 & 72.08 & 2.75 \\
Point 8 & 3.95 & 1.18 & 20.18 & 0.15 & 2.69 & 60.23 & 2.75 & 8.86 \\
\hline
\end{tabular}

Table 4. Variation in peak position, d-spacing and lattice parameter of alloy 625 additively manufactured samples sintered at temperatures from $1200{ }^{\circ} \mathrm{C}$ to $1300{ }^{\circ} \mathrm{C}$.

\begin{tabular}{|c|c|c|c|}
\hline $\begin{array}{c}\text { Sintered at } \\
{\left[{ }^{\circ} \mathrm{C}\right]}\end{array}$ & $\begin{array}{c}2 \theta \\
{\left[{ }^{\circ}\right]}\end{array}$ & $\begin{array}{c}d \\
{[\AA]}\end{array}$ & $\begin{array}{c}\text { Lattice parameter } \\
{[\AA]}\end{array}$ \\
\hline 1200 & 51.415 & 2.0621 & 3.57171 \\
\hline 1220 & 51.401 & 2.0630 & 3.57261 \\
\hline 1240 & 51.391 & 2.0631 & 3.57325 \\
\hline 1260 & 51.382 & 2.0634 & 3.57383 \\
\hline 1280 & 51.371 & 2.0638 & 3.57455 \\
\hline 1290 & 51.357 & 2.0645 & 3.57545 \\
\hline 1300 & 51.331 & 2.0653 & 3.57714 \\
\hline
\end{tabular}


Table 5. Compositional analysis in wt.-\% of the points determined on the fracture surface of the sintered sample in Figure 12.

\begin{tabular}{|c|c|c|}
\hline Element & $\begin{array}{c}\text { Point 1 } \\
{[\text { wt.-\% }]}\end{array}$ & $\begin{array}{c}\text { Point 2 } \\
\text { [wt.-\%] }\end{array}$ \\
\hline $\mathrm{Ni}$ & 60.49 & 37.04 \\
\hline $\mathrm{Nb}$ & 3.58 & 6.36 \\
\hline $\mathrm{Mo}$ & 9.38 & 4.91 \\
\hline $\mathrm{Fe}$ & 2.63 & 6.18 \\
\hline $\mathrm{Mn}$ & 0.26 & 1.62 \\
\hline $\mathrm{Cr}$ & 21.51 & 11.46 \\
\hline $\mathrm{Ti}$ & --- & 0.47 \\
\hline $\mathrm{C}$ & 0.42 & 33.97 \\
\hline $\mathrm{O}$ & 1.43 & --- \\
\hline
\end{tabular}

\section{Figure captions}

Figure 1. Image of a tensile sample printed from alloy 625 powder with BJP.

Figure 2. SEM images of alloy 625 powders (a,b) morphology and cross sectional microstructure, (c) XRD pattern (X-ray source is Co-k $\mathrm{k}_{\alpha}$ ) and (d) microTrac particle size analysis. Figure 3. MicroCT scans of the as-received alloy 625 powders contained in a plastic straw. Details of the scans are shown, identifying porosity within powder particles, indicated by arrows. Figure 4. DSC curve of alloy 625 powder.

Figure 5. Optical micrographs of polished samples after sintering at different temperatures (a) $1200{ }^{\circ} \mathrm{C}$, (b) $1220{ }^{\circ} \mathrm{C}$, (c) $1240{ }^{\circ} \mathrm{C}$, (d) $1260{ }^{\circ} \mathrm{C}$, (e) $1280{ }^{\circ} \mathrm{C}$, (f) $1290{ }^{\circ} \mathrm{C}$, (g) $1300{ }^{\circ} \mathrm{C}$ with a holding time of $4 \mathrm{~h}$ (magnification 100x and 1000x).

Figure 6. Optical micrographs of etched samples after sintering at (a) $1280{ }^{\circ} \mathrm{C}$, (b) $1290{ }^{\circ} \mathrm{C}$ and $1300{ }^{\circ} \mathrm{C}$ for $4 \mathrm{~h}$.

Figure 7. MicroCT image of an as-printed, alloy 625 powder sample.

Figure 8. (a) Relative density of samples sintered at different temperatures ranging from 1200 to $1300{ }^{\circ} \mathrm{C}$. Results were obtained by Archimeds' method and optical micrographs analyzing by ImageJ. (b) Shrinkage of the sintered samples depending on sintering temperature.

Figure 9. SEM images taken from the cross-section of the alloy 625 powders sintered at (a) 1200 ${ }^{\circ} \mathrm{C}$, (b) $1240{ }^{\circ} \mathrm{C}$, (c) $1280{ }^{\circ} \mathrm{C}$, (d) $1290{ }^{\circ} \mathrm{C}$ and (e) $1300{ }^{\circ} \mathrm{C}$.

Figure 10. The XRD patterns of the samples sintered at different temperatures from 1200 to $1300{ }^{\circ} \mathrm{C}$ for $4 \mathrm{~h}$ (left). Shifting of $\mathrm{Ni}-\gamma$ (111) XRD peak (between $51.3^{\circ}$ and $51.6^{\circ}$ ) during sintering at different temperatures (right).

Figure 11. (a) Microhardness values of the samples sintered at different temperatures for $4 \mathrm{~h}$ and (b) average tensile curves of the fully-densified samples.

Figure 12. Fracture surface with corresponding EDS elemental analysis results of the sintered sample at $1280{ }^{\circ} \mathrm{C}$ for $4 \mathrm{~h}$. 


\section{As-printed sample}

\section{Sintered sample}

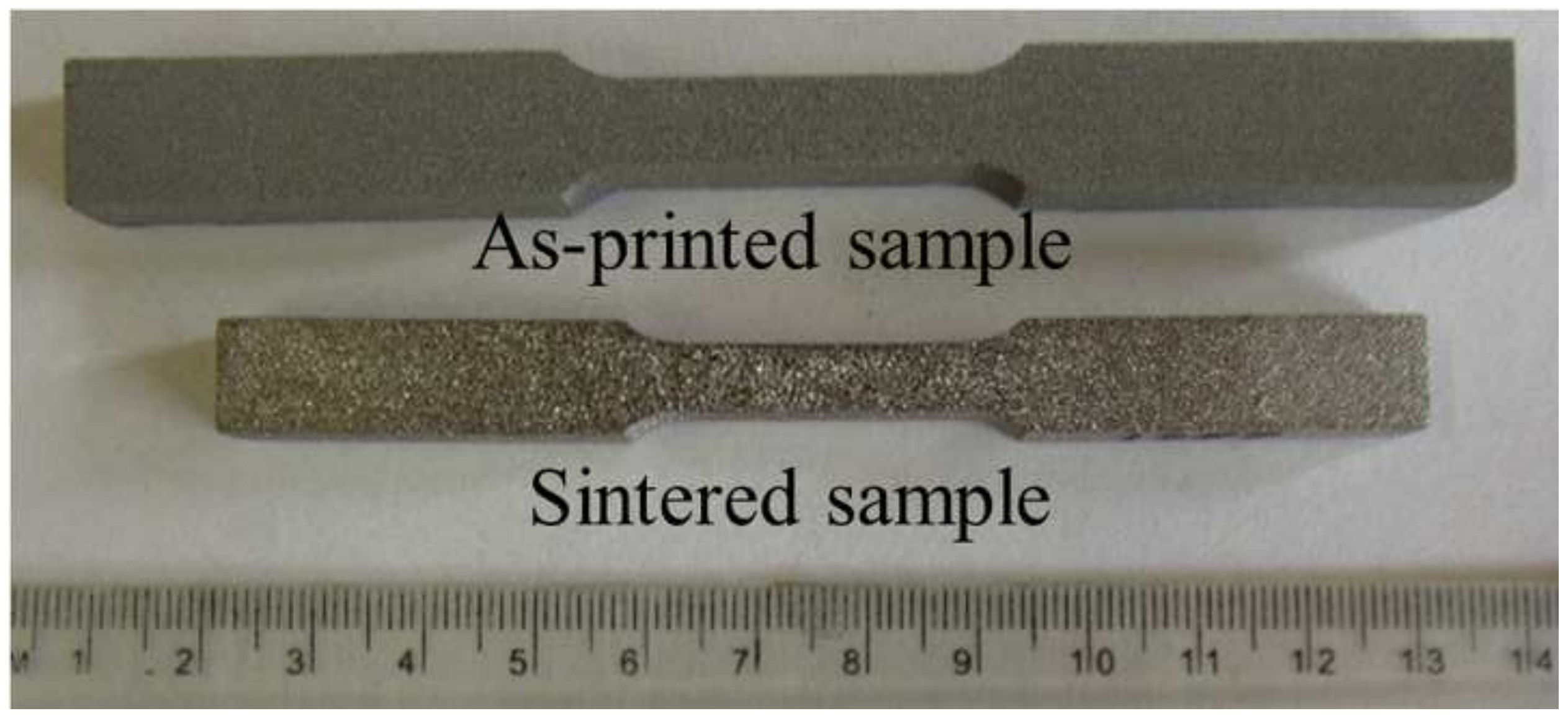



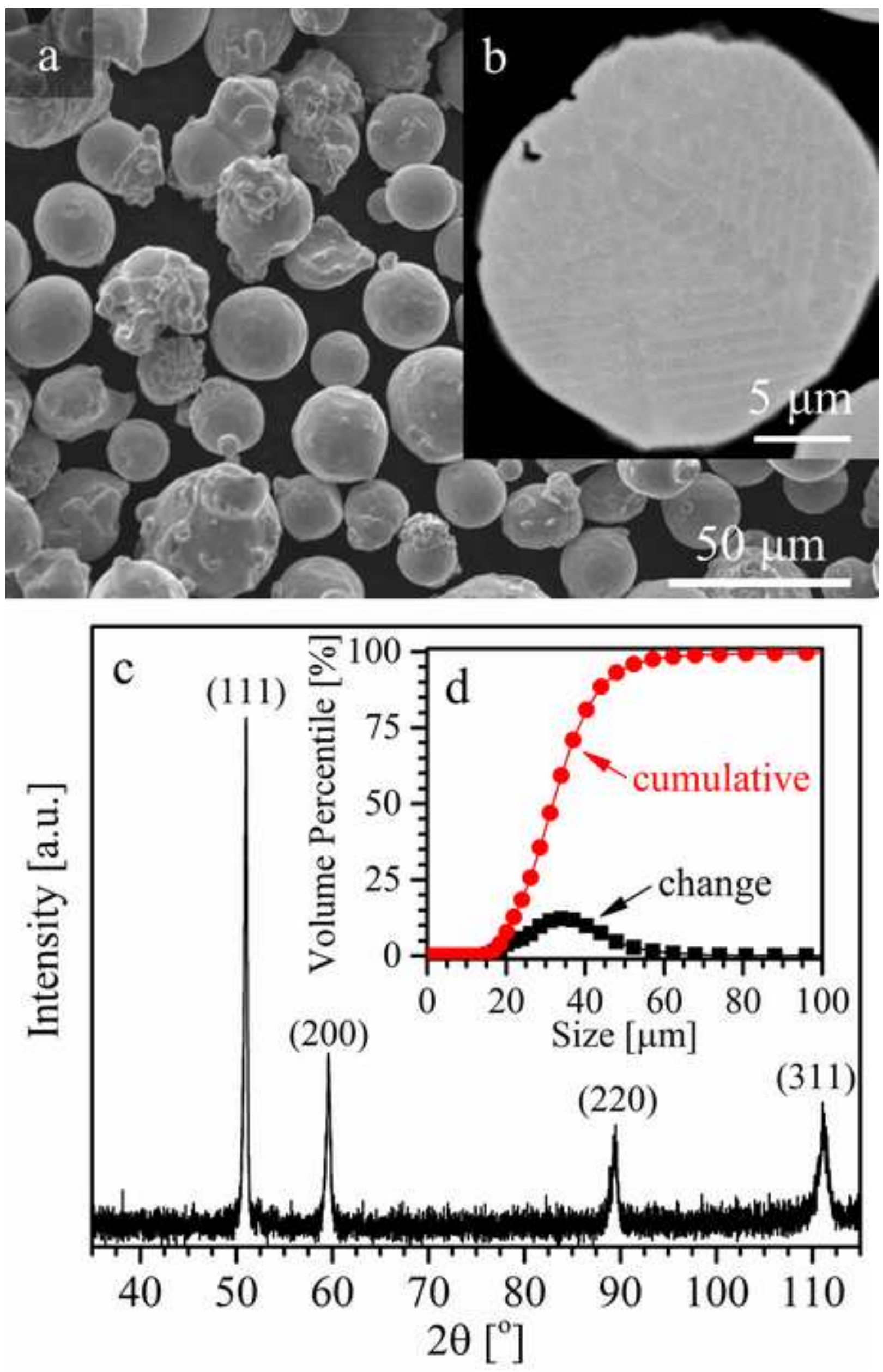


\section{$0.1 \mathrm{~mm}$}

plastic straw

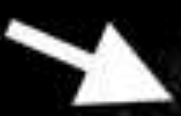

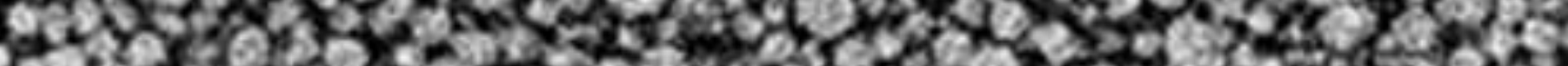

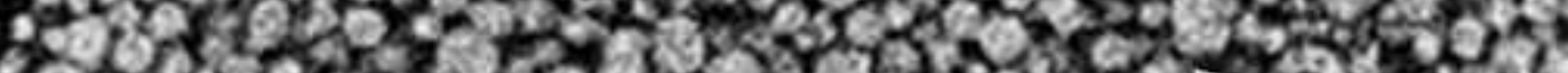

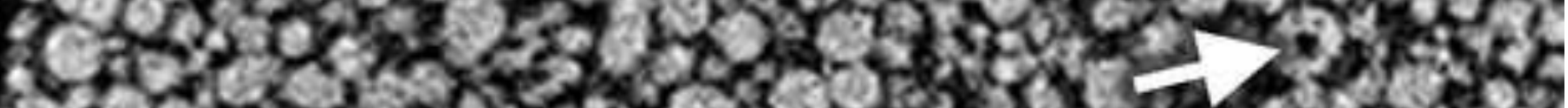

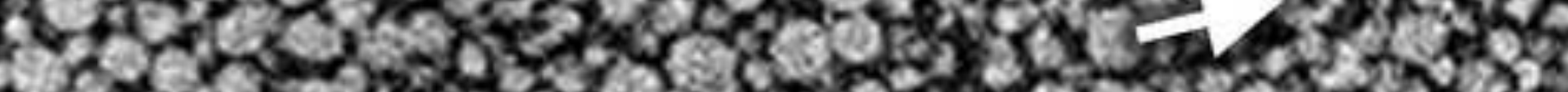

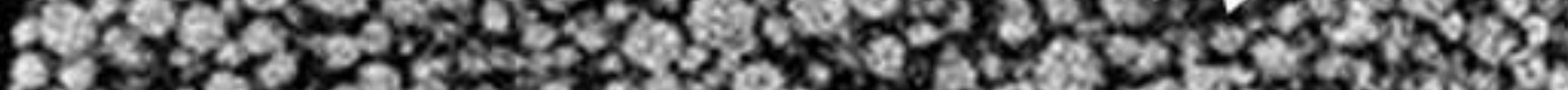

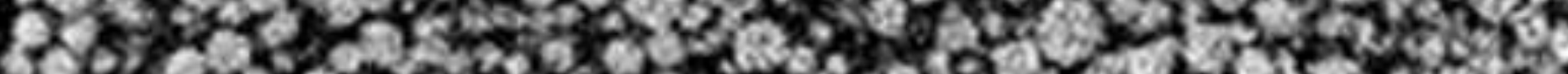

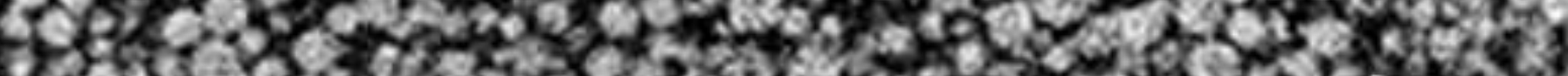

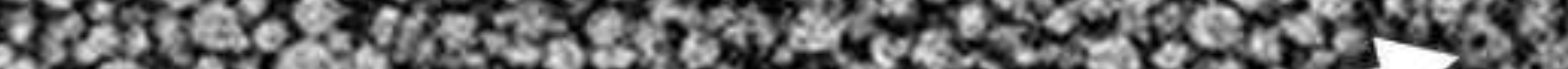

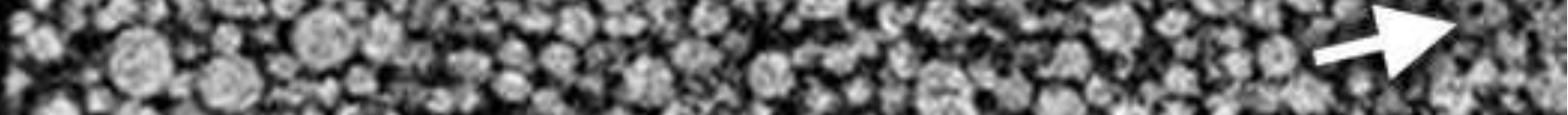
ot rasors 

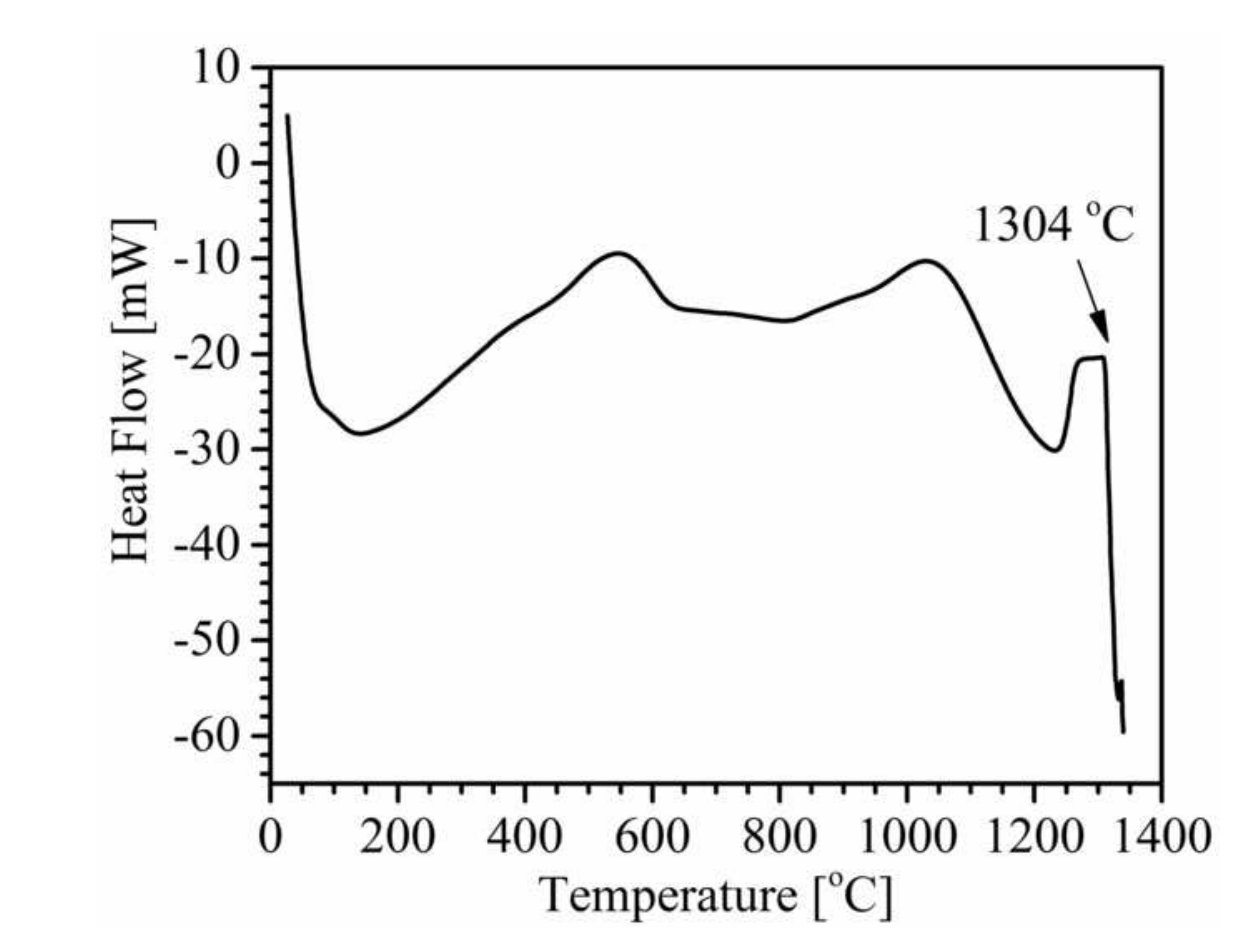

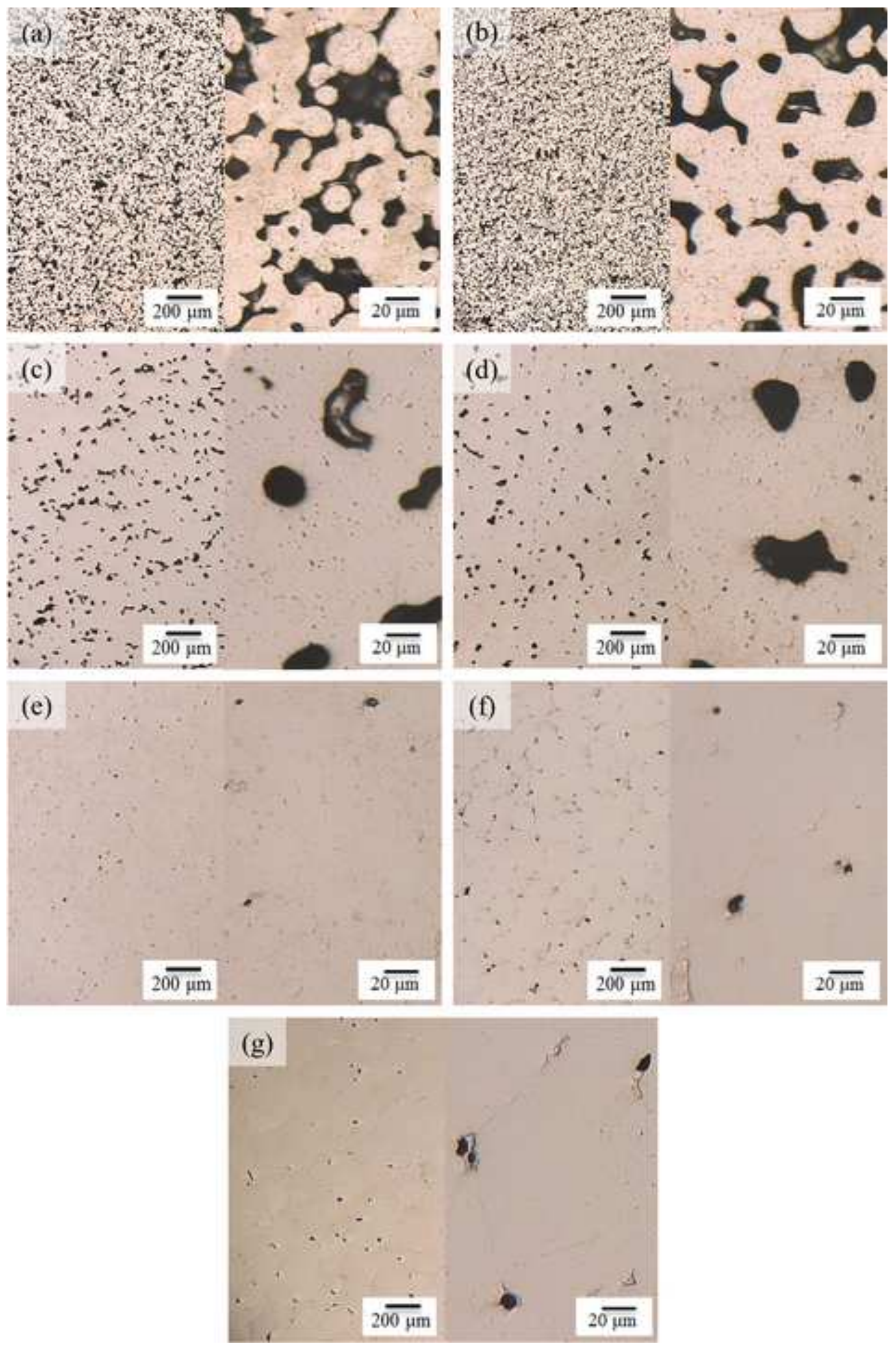

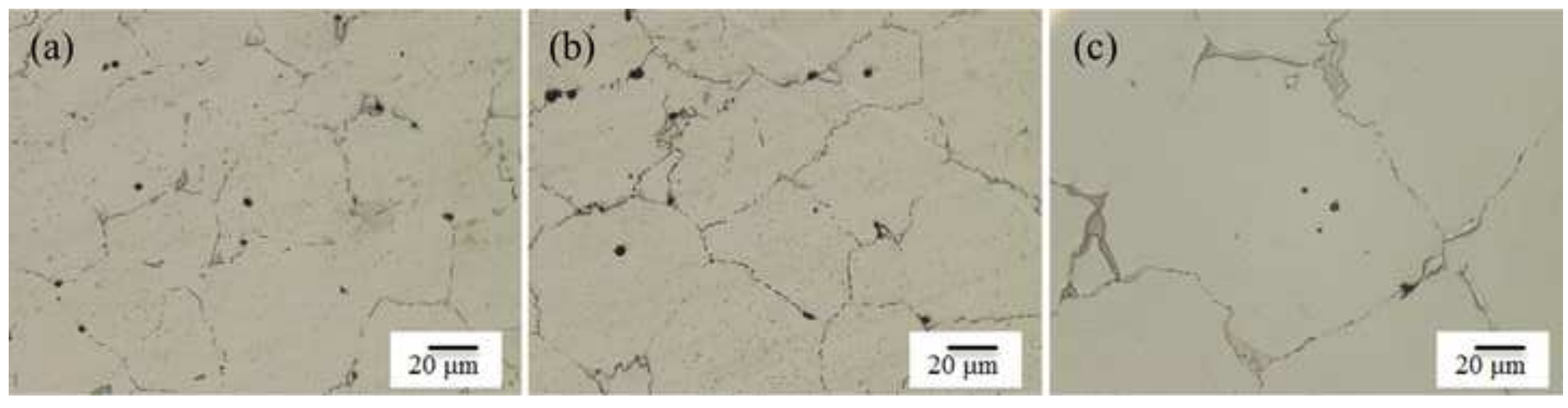


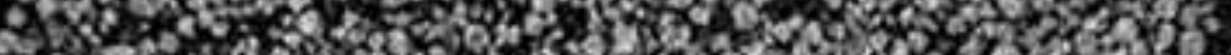

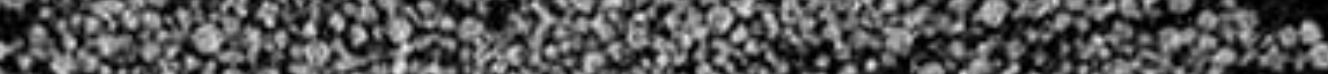
Pow c.

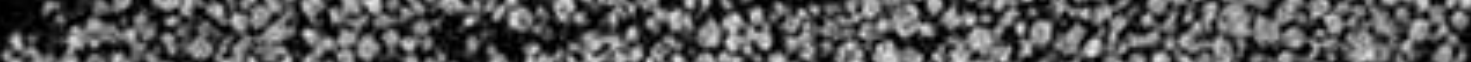

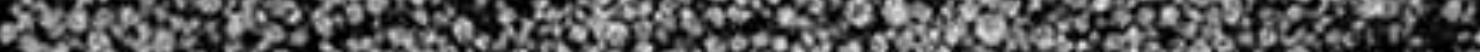

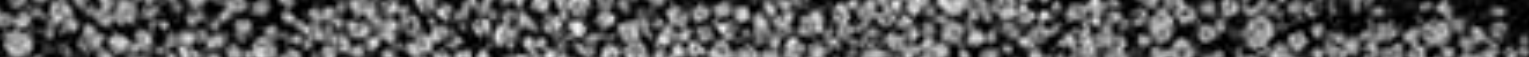

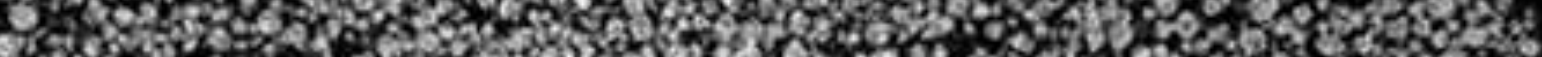

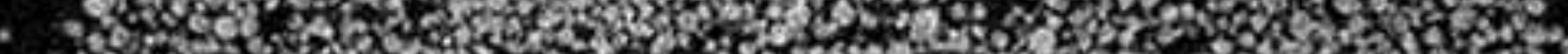
ward

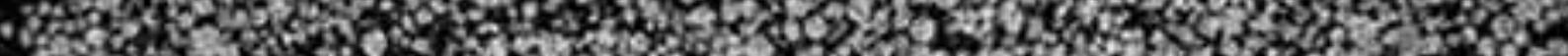
If

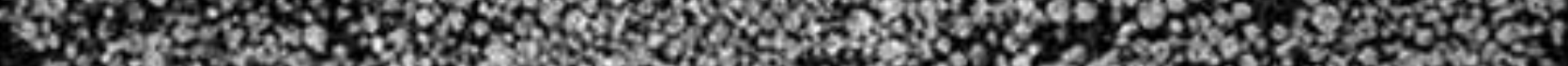

r.w.

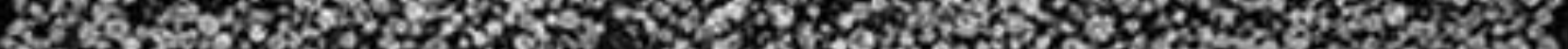

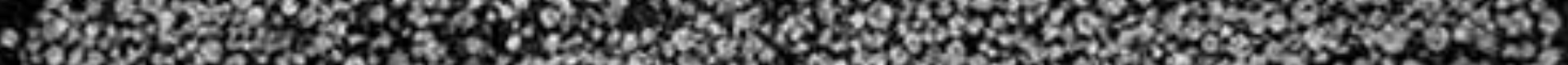

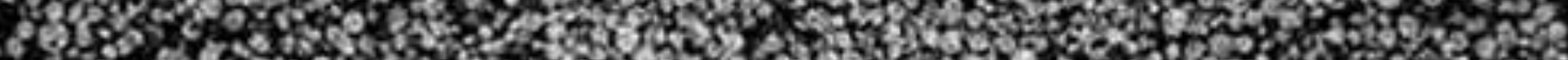

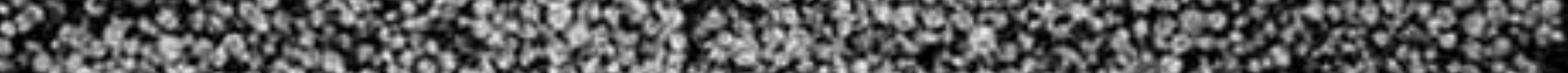

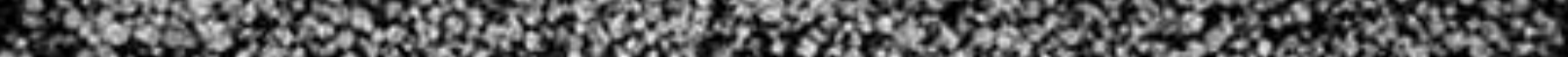
9.

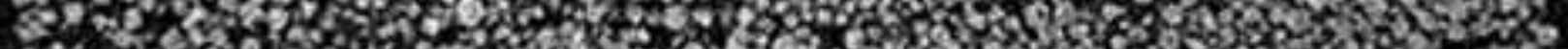

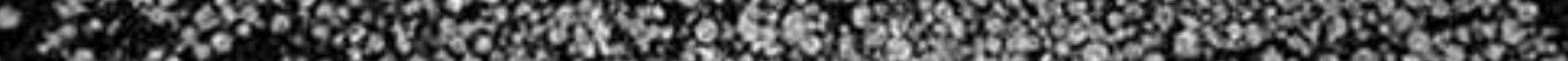

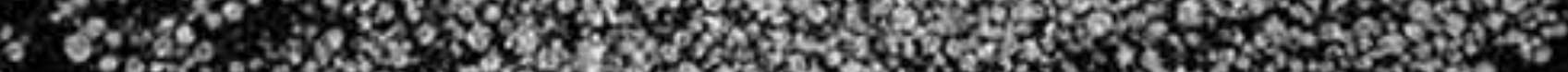

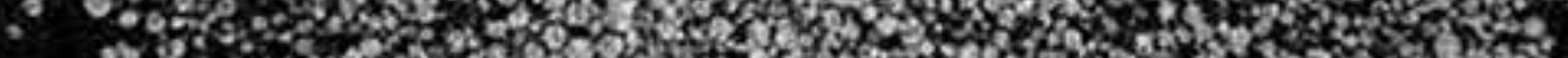
Al

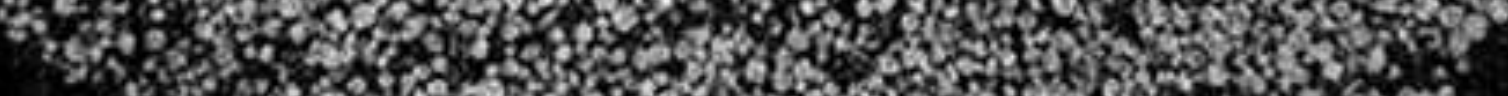
ex-

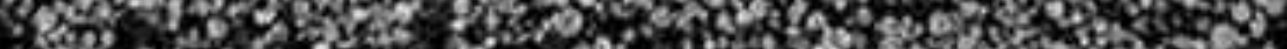

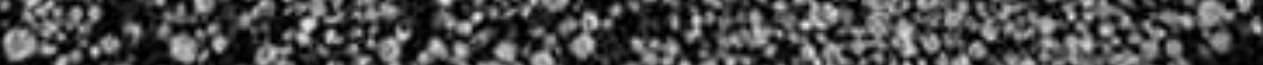

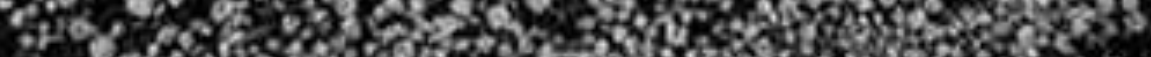
4 iof

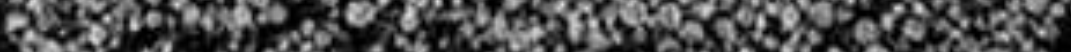

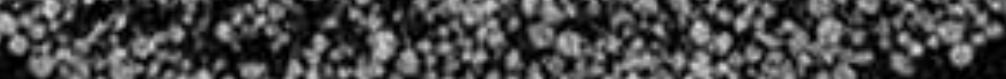

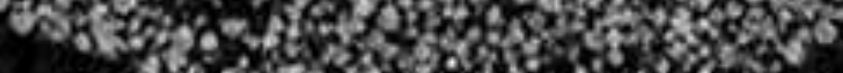

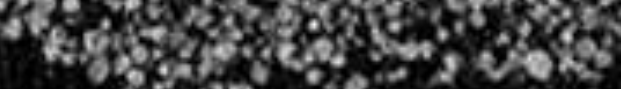

40

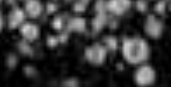

$0.5 \mathrm{~mm}$

(9) - 2 

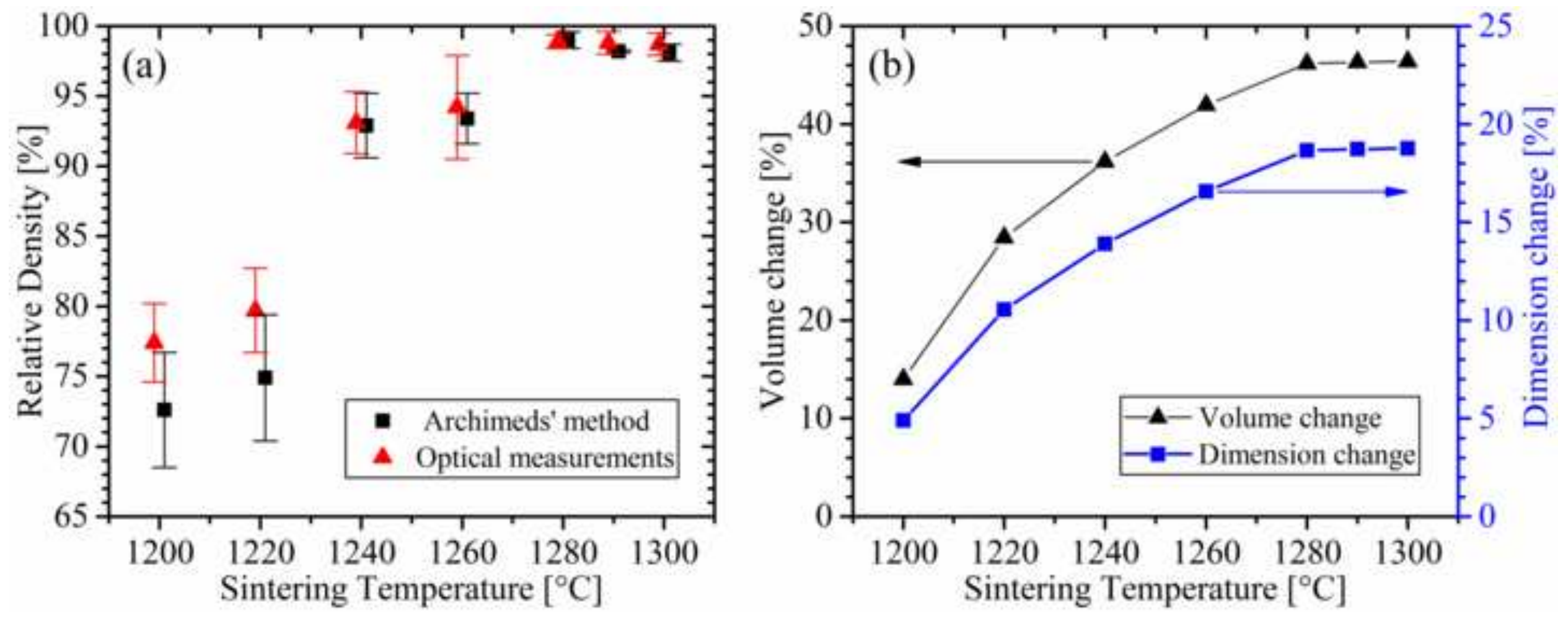


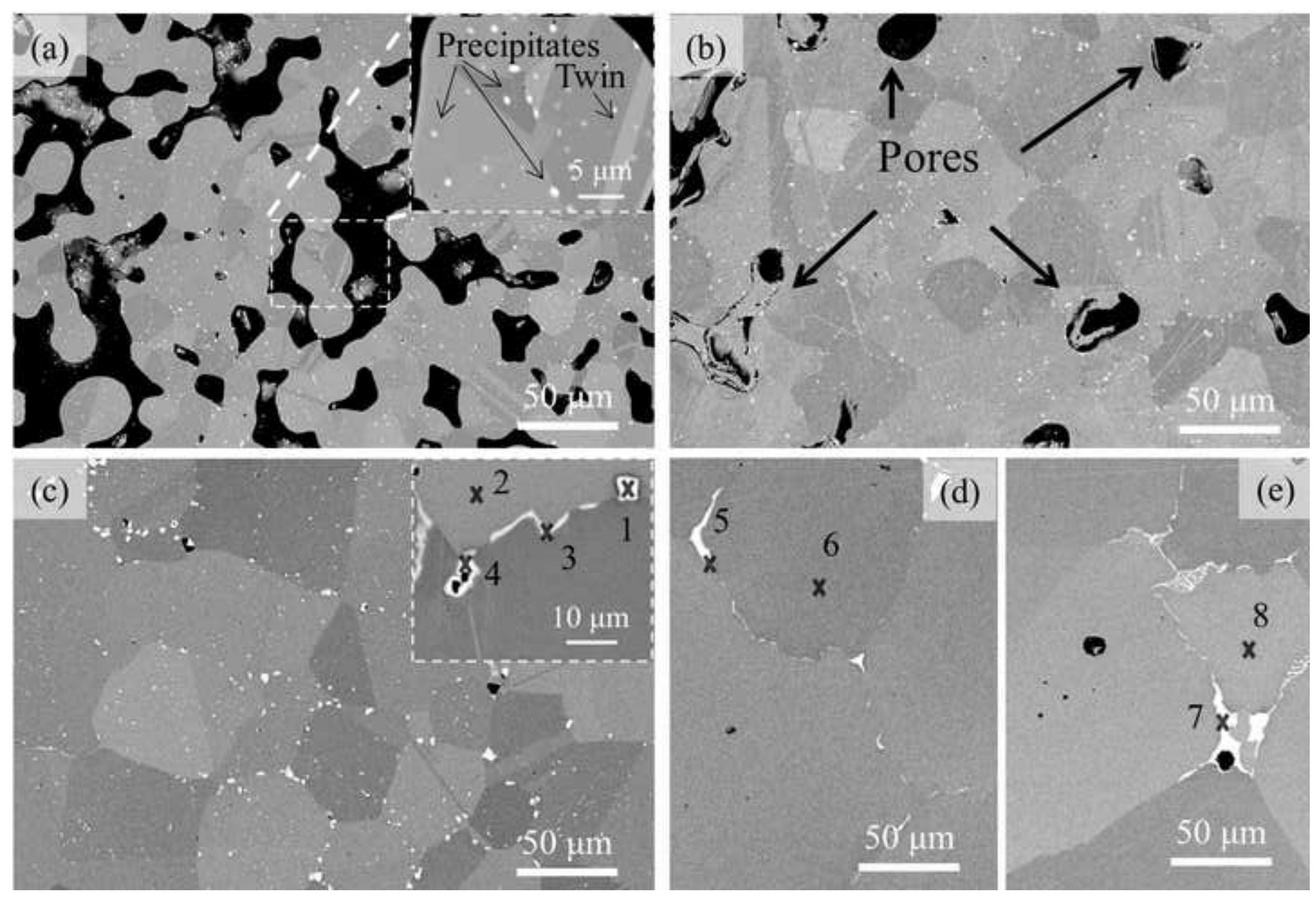




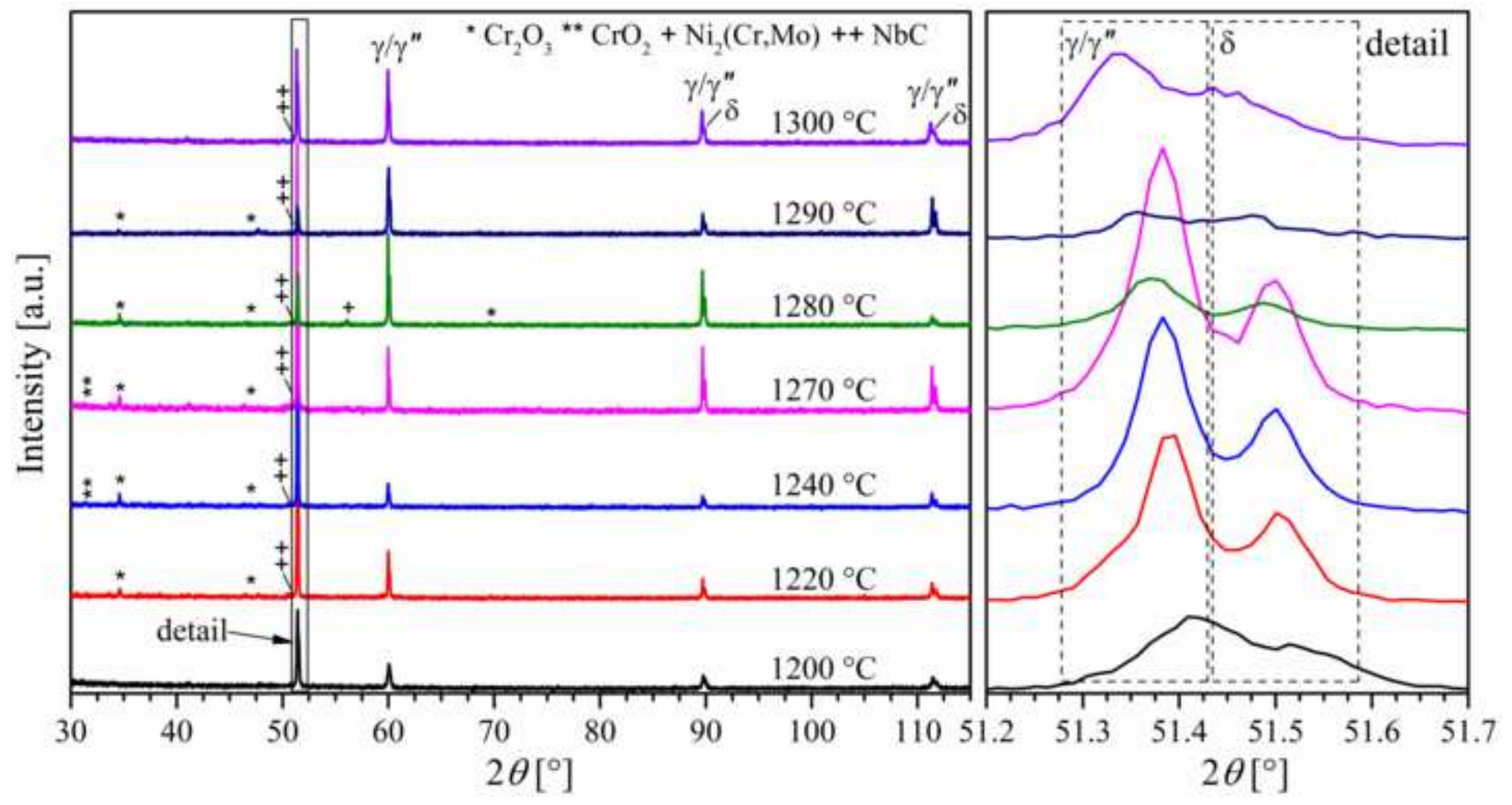




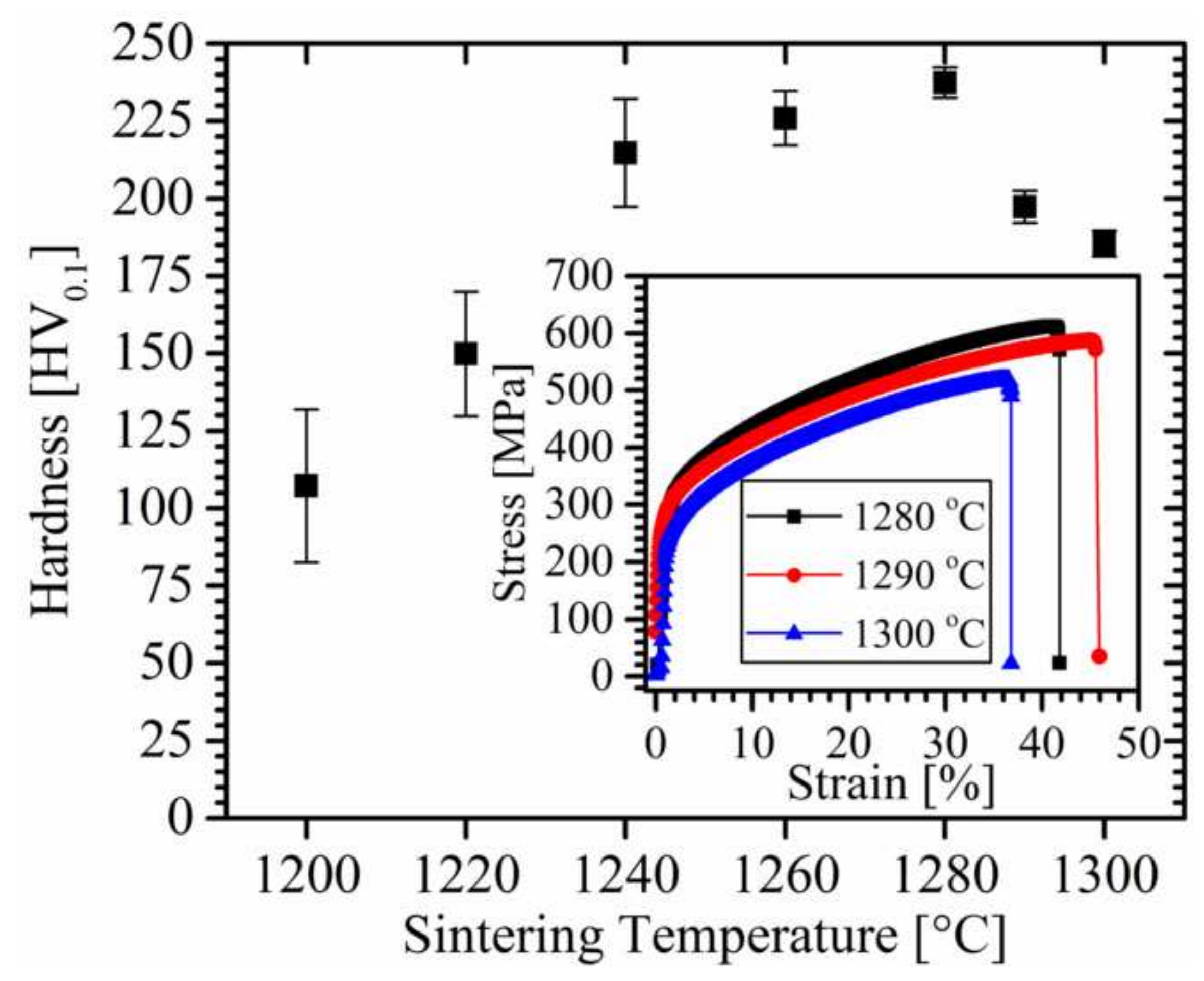



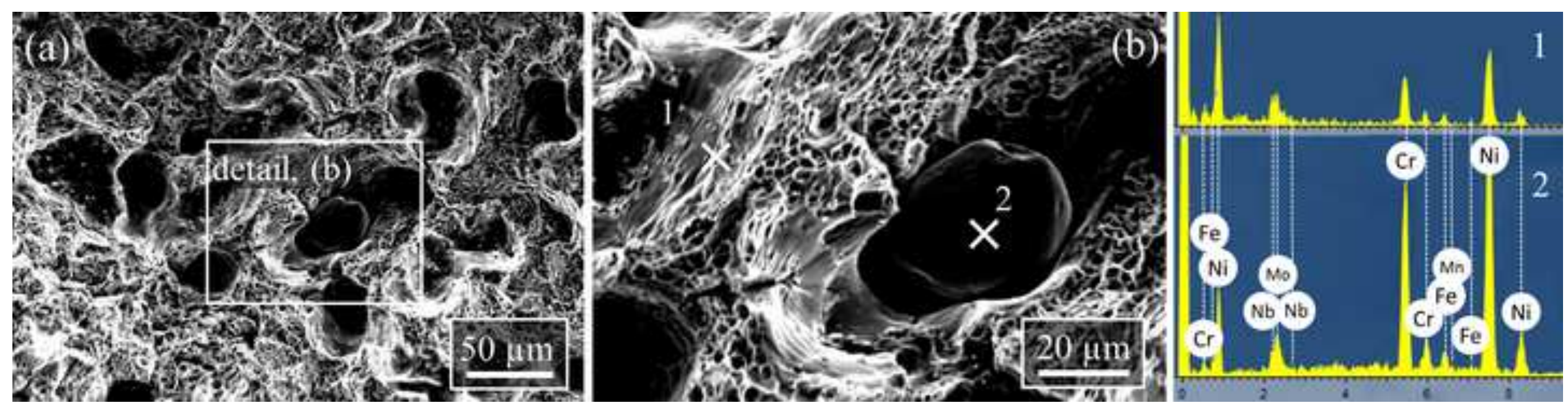


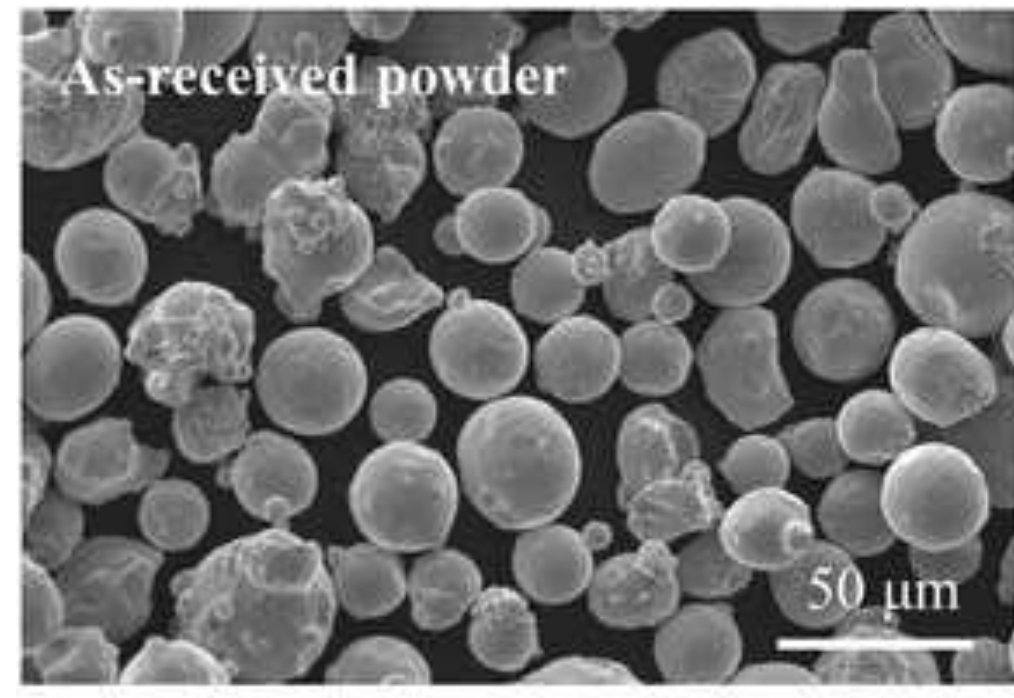

Binder jet printed alloy 625

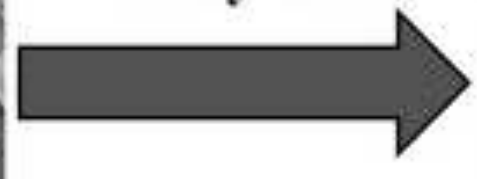

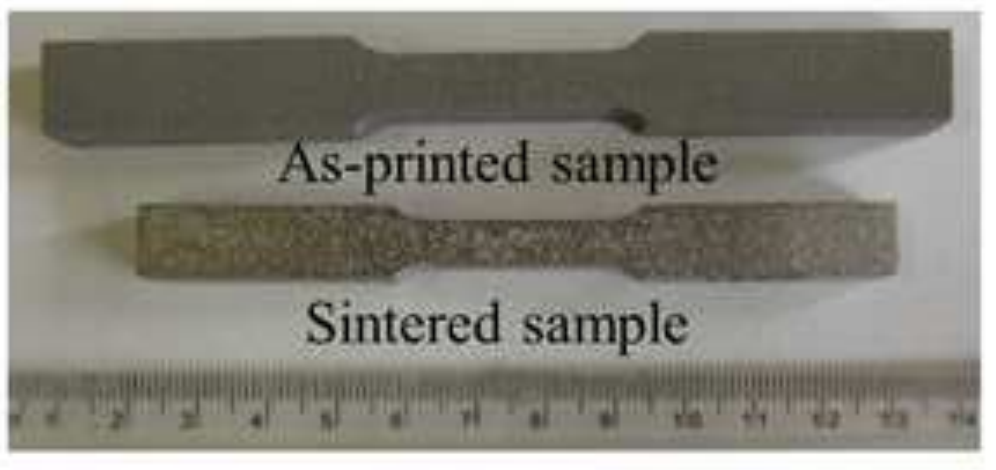
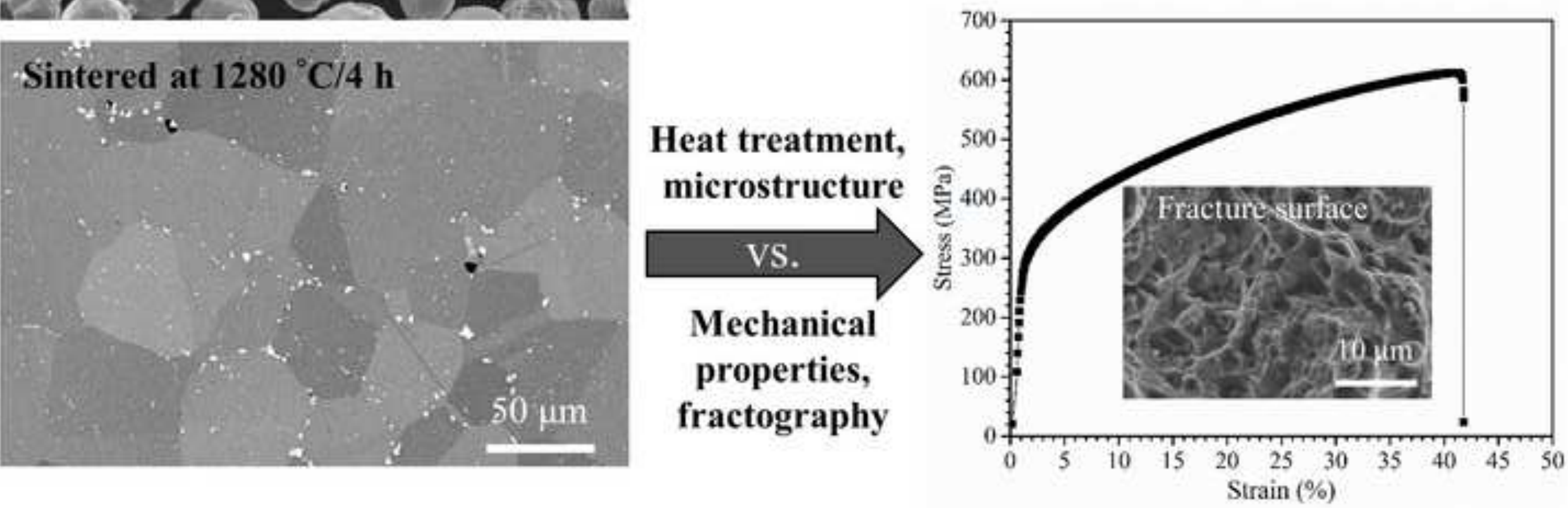